\title{
Theoretical Analysis on Pollution Flashover Voltage Prediction Based on Leakage Current of Porcelain Insulator in Service
}

\author{
Lei Song $^{1}$ Fuzeng Zhang $^{2}$ Xidong Liang ${ }^{1}$ Yifan Liao $^{2}$ \\ ${ }^{1}$ Department of Electrical Engineering, Tsinghua University, Beijing, China \\ ${ }^{2}$ Electric Power Research Institute, CSG, Guangzhou, China
}

\begin{abstract}
In this paper, leakage current obtained by laboratory was derived to calculate the pollution flashover voltage of porcelain insulators. On this basis, this paper analyzed the basic theory of prediction of pollution flashover based on leakage current monitored in service. At the same time, the calculation results and the test results of pollution flashover voltage were compared. The results showed that the difference of flashover voltage between calculation results and test results was less than $5 \%$. It is proved that the calculation method for evaluating the flashover risk by monitoring the leakage current proposed in this paper was effective.
\end{abstract}

Keywords: porcelain insulator, DC, leakage current, pollution flashover voltage

\section{Introduction}

Pollution Flashover seriously affects the safety of the power system. The process of pollution flashover often accompanies by a change of leakage current. Leakage current is a convenient online monitoring tool which has been studied a lot by domestic and foreign scholars. On this basis, this paper analyzed the basic theory of prediction of pollution flashover based on leakage current monitored in service. At the same time, the calculation results and the test results of pollution flashover voltage were compared.

\section{Test facilities and test method for leakage current measurement}

\subsection{Test facilities and test specimens}

The test was carried out in fog chamber. The test schematic diagram of test facilities was showed in Figure 1. The test was supported by a DC power supply which can provide an output of $\pm 1000 \mathrm{kV}$. Negative feedback control mode was used to control the output of the power supply. The ripple factor of the test voltage was less than $3 \%$. The relative voltage drop occurring during individual tests resulting in $500 \mathrm{~mA}$ leakage current which continued for $500 \mathrm{mS}$ did not exceed $5 \%$.It met the IEC standard requirement [1].

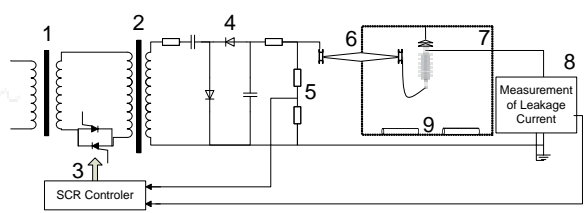

1- Regulator 2- Testing Transformer 3-SCR 4Double Voltage Circuit 5- Resistive Voltage Divider 6- Wall Bushing 7-Fog Chamber 8Measurement of Leakage Current 9-Steam Generator

Figure 1: The experimental system. 
The anti-fog porcelain insulators were tested and its main dimensions were illustrated in Figure 2.

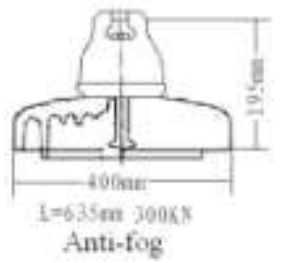

Figure 2: Configurations and main dimension of test insulators.

\subsection{Test procedures}

The solid layer method was used. The main test procedures were introduced as follows.

- Cleaning. Clean the surface of the insulators.

- Contaminating. The calculated amount of salt $(\mathrm{NaCl})$, kaolin and water were made into suspension. Then the suspension was brushed on the surface of the insulator.

- Drying. After the contaminating, the layer should be left to dry prior to the test.

- Arrangement. The insulator should be hanged in the fog chamber and the wire was connected.

- Applying the test voltage and inputting the steam.

- Measuring the leakage current.

\section{Test results and analysis}

\subsection{Maximum leakage current of the surface of the insulator}

In the initial stage, the surface of the insulator was becoming wetting because of the fog. The leakage current was increasing while the conductivity of surface was increasing. So the resistivity of the surface was reducing. And then the insulator was saturated moisture and the maximum leakage current was gotten. Subsequently, the contamination and salinity on the insulator surface would gradually be lost. The leakage current was reducing. So there was a maximum value for the leakage current.

Saturated leakage current of porcelain insulator strings was measured in different equivalent salt deposit density (ESDD) and non-soluble deposit densities (NSDD). The results were shown in Table 1 . The maximum value of the leakage current was related to ESDD, NSDD, the applied voltage and the length of insulator strings. If the length of insulator strings was ignored, discussing about the maximum leakage current had no meaning. On based of previous studies, this paper used the insulator surface resistance which was the quotient of applied voltage and leakage current.

Table 1: Maximum value of leakage current and value of applied voltage of test insulators in different ESDD ( $\mathrm{NSDD}=1.0 \mathrm{mg} / \mathrm{cm}^{2}$ ).

\begin{tabular}{|c|c|c|c|}
\hline $\begin{array}{c}\mathrm{ESDD} \\
\left(\mathrm{mg} / \mathrm{cm}^{2}\right)\end{array}$ & $\begin{array}{c}\text { Applied } \\
\text { voltage } \\
(\mathrm{kV})\end{array}$ & $\begin{array}{c}\text { Length of } \\
\text { insulator } \\
\text { strings } \\
\text { (units) }\end{array}$ & $\begin{array}{c}\text { Maximum } \\
\text { leakage } \\
\text { current } \\
(\mathrm{mA})\end{array}$ \\
\hline 0.03 & 720 & 37 & 170.13 \\
\hline 0.05 & 720 & 50 & 168.24 \\
\hline 0.1 & 720 & 85 & 247.41 \\
\hline 0.2 & 740 & 110 & 362.85 \\
\hline
\end{tabular}

\subsection{Relationship between surface re- sistance and length of insulator strings}

Minimum surface resistivity of insulator reflected the value of surface resistivity when the insulator got the saturated leakage current. It could be calculated according to Formula 1.

$$
R=\frac{U_{d}}{I_{m}}
$$

$R$ was minimum surface resistivity. $U_{\mathrm{d}}$ was applied voltage. $I_{\mathrm{m}}$ was saturated leakage current of insulators. 
When the ESDD was $0.03 \mathrm{mg} / \mathrm{cm}^{2}$, the relationship between surface resistance and length of insulator strings was shown in Figure 3.

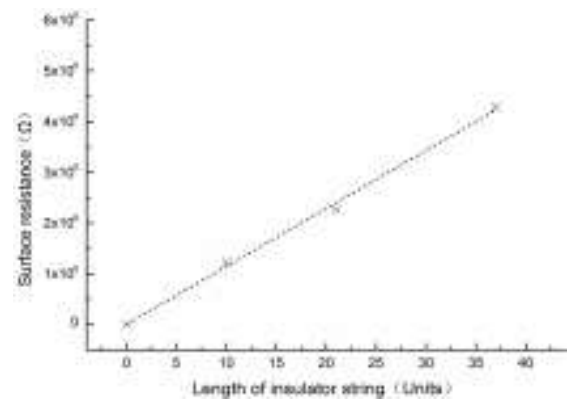

Figure 3: The relationship between surface resistance and length of insulator strings.

It could be concluded from Figure 3 that the relationship between surface resistance and length of insulator string was approximately linear. Due to the presence of a linear relationship, the law of one unit insulator could be studied to reflect the law of whole strings.

\subsection{Calculation of surface resistivity of one unit insulator}

While the surface resistance had been calculated, the surface resistivity could be calculated according to Formula 2.

$$
r=\frac{R}{F}
$$

$\rho$ was surface resistivity. $R$ was minimum surface resistivity. $F$ was shape factor of porcelain insulator tested in this paper. The shape factor $F$ could be calculated according to Formula 3.

$$
F=\text { ò }_{0}^{L} \frac{1}{C(L)} d L
$$

$L$ was creepage distance of porcelain insulator tested in this paper. $C$ was circumference which was the function of creepage distance.

The shape factor $F$ of porcelain insulator tested in this paper was 0.953 . There- fore the surface resistivity was calculated. The results were shown in Table 2 .

Table 2: Surface resistivity when the insulator was contaminated by different ESDD

\begin{tabular}{ccccc}
\hline $\begin{array}{c}\mathrm{ESDD} \\
\mathrm{mg} / \mathrm{cm}^{2}\end{array}$ & 0.03 & 0.05 & 0.1 & 0.2 \\
\hline $\begin{array}{c}\rho \\
(\mathrm{k} \Omega / \mathrm{cm})\end{array}$ & 120.02 & 89.81 & 35.93 & 19.45 \\
\hline
\end{tabular}

\section{Flashover voltage calculated on ba- sis of Obenaus formula and surface resistivity of insulator}

\subsection{Calculation of pollution flashover of porcelain insulator}

In this paper, the influence of the arc foot was ignored. The insulator was equivalent to a cylindrical. The electrodes were on the upper and lower surfaces of the cylinder. The equivalent cylinder and the insulator had the same equivalent diameter, creepage distance and form factor. Parameters of equivalent cylindrical and insulator were shown in Table 5. Meanwhile, it is considered that SDD on different area of insulator surface was uniformly. It meant that different area of insulator surface had the same surface resistivity. The equivalent diameter $D$ could be calculated according to Formula 4.

$$
D=\frac{L}{F}
$$

The Obenaus model formula was shown as Formula 5 [2].

$$
U=A x I^{-n}+R(x) I
$$

$U$ was pollution flashover voltage of porcelain insulator. $I$ was leakage current flew on the surface of equivalent diameter cylinder. $R(x)$ was resistance of residual contaminated layer and $x$ was the length of arc.

The values of $\mathrm{A}$ and $\mathrm{n}$ were not exclusive in international opinions. Some scholars measured it in the normal air while some of them measured it in steam. This paper used the results measured by 
Professor Guan in Tsinghua University. A was 138 while $\mathrm{n}$ was 0.69 [3].

$R(x)$ could be calculated according to Formula 6.

$$
R(x)=r \frac{L-x}{p D}=r F \frac{L-x}{p L}
$$

Formula 6 was taken into 5 ,then

$$
U=A x I^{-n}+r F \frac{L-x}{p L} I
$$

A function of $x$ about $I$ and $U$ was gotten

$$
x=\frac{U p L-r F I L}{A p L I^{-n}-r F I}
$$

$x$ was the dependent variable. $I$ and $U$ was the independent variables. For different values of $U$, a family $x$ - $I$ curves could be drawn, as shown in Figure 4 . When $x$ was less than $L$, indicating that the arc did not complete development on the surface of insulator, and when $x$ was greater than or equal to $L$, indicating the arc had completed the development. This showed that there was a point in this curve. At the point the arc would complete the mutation, and it was the critical point of flashover.

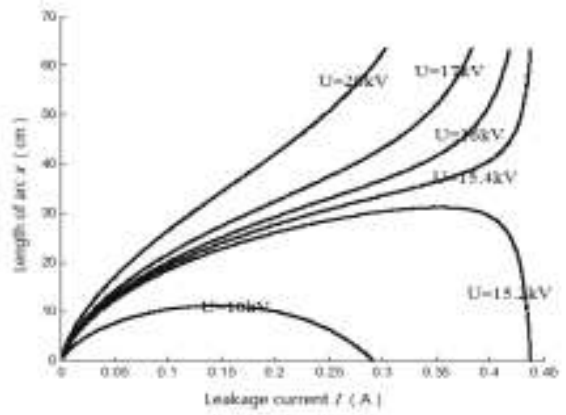

Figure 4: The relationship between $x, I$ and $U$

In Figure 4, when the voltage value $U<15.3 \mathrm{kV}$, the curve had a maximum, the arc could not develop to the highest point. When $U>15.3 \mathrm{kV}$ arc could finish the development. So $U=15.3 \mathrm{kV}$ was critical point of flashover voltage.

\subsection{Verify of the result}

The comparison of test results and calcu- lated results was shown in Table 3 .

The results showed that the difference of flashover voltage between calculation results and the test results was less than $5 \%$. It is proved that the calculation method was effective.

Table 3: Comparison of test results and calculated results $(\mathrm{kV})$

\begin{tabular}{cccc}
\hline & Test & Calculation & $\begin{array}{c}\text { Devia- } \\
\text { tion }\end{array}$ \\
\hline $\begin{array}{c}\text { Flashover } \\
\text { voltage }\end{array}$ & 14.6 & 15.3 & $4.6 \%$ \\
\hline
\end{tabular}

\section{Conclusion}

The relationship between surface resistance and length of insulator string was approximately linear. The difference of flashover voltage between calculation results and the test results was less than $5 \%$. It is proved that the calculation method for evaluating the flashover risk by the leakage current proposed was effective.

\section{Acknowledgements}

This work was supported by National Engineering Laboratory for Ultra High Voltage Engineering Technology

(NEL201202)

\section{References}

[1] IEC 61245: 1993, “Artificial Pollution Test for Insulators Used for DC Systems".

[2] F. A. M. Rizk, "Mathematical Models for Pollution Flashover", Electra, Vol. 78, pp. 71-103, 1981.

[3] Z. C. Guan and R. Y. Zhang, "Calculation of dc and ac Flashover Voltage of Polluted Insulators", IEEE Trans. Electrical Insulation, Vol. 25, No. 4, pp. 723-729, 1990. 